\section{What the doctor ordered}

\section{John Galloway}

Historical Perspectives on the Role of the MRC. Edited by Joan Austoker and Linda Bryder. Oxford University Press: 1989. Pp.259. £30, \$49.95.

A RESEARCH organization is judged - or should be judged - by what it is doing, not by what it has done. The scientific past tends to be insignificant compared with its present: "science swamps its own history", as Barry Barnes says in his book About Science (Blackwell, 1985).

Nevertheless, historians (and others) do write the histories of research institutions, some of which clearly like to have their histories, or at least authorized versions of them, written up. The UK Medical Research Council's 'authorized' version was written by Sir Landsborough Thomson, retired second secretary of the council, and published in 1973. What we have in the present volume is not an alternative complete history of the MRC but rather ten essays about different aspects of its work, written with one exception by professional historians. The exception is Sir Christopher Booth, last director of the Clinical Research Centre who is, I think it fair to say, a distinguished amateur historian.

Sir Landsborough's history, written as it was by a man who spent most of his working life with the MRC, is presumbly the nearest thing an institution can have to an autobiography. It is this rather than the fact that it was authorized that is worth remembering - the essays in the present collection are in a sense no less authorized; they were written with considerable access to the MRC's archives, or at least such as were left of them. (One result of Sir Landsborough's version, if I remember correctly from my days at MRC, was that many archives were destroyed, an action justified apparently by the belief that whatever history they contained had been transferred intact to his book.) The writers also had access to members of MRC staff past and present. What they could bring to the task, which Sir Landsborough, of necessity, could not do, is an alien viewpoint - a searching, intrusive look from outside.

The viewpoint is alien in more senses than one. The research described in these essays was almost without exception done by men, as was the work of the committees monitoring its progress and taking decisions about it. But five out of the eight essayists are women. There is a lesson here. For those who believe - and who can blame them? - that medical research in Britain began round about
1950 with the startling insights provided by molecular biology (Nobel prizewinners Crick, Watson, Sanger, Perutz and Kendrew all worked in MRC laboratories), these essays may come as a surprise. To begin with, almost all the research they relate took place before then. In scientific terms this is not merely history, but largely ancient history. And second, the research is very applied: tuberculosis, tropical medicine, industrial health, public health (in two essays), applied new research findings and new statistical methods to what were perceived to be the pressing medical and social problems of the day. Indeed, it is argued persuasively by Linda Bryder that it was explicitly the problem of tuberculosis - which assumed enormous proportions in the early years of this century - that brought the MRC into being. Concern that Britain was lagging behind Germany in the treatment of tuberculosis and so in 'national efficiency' led to this disease

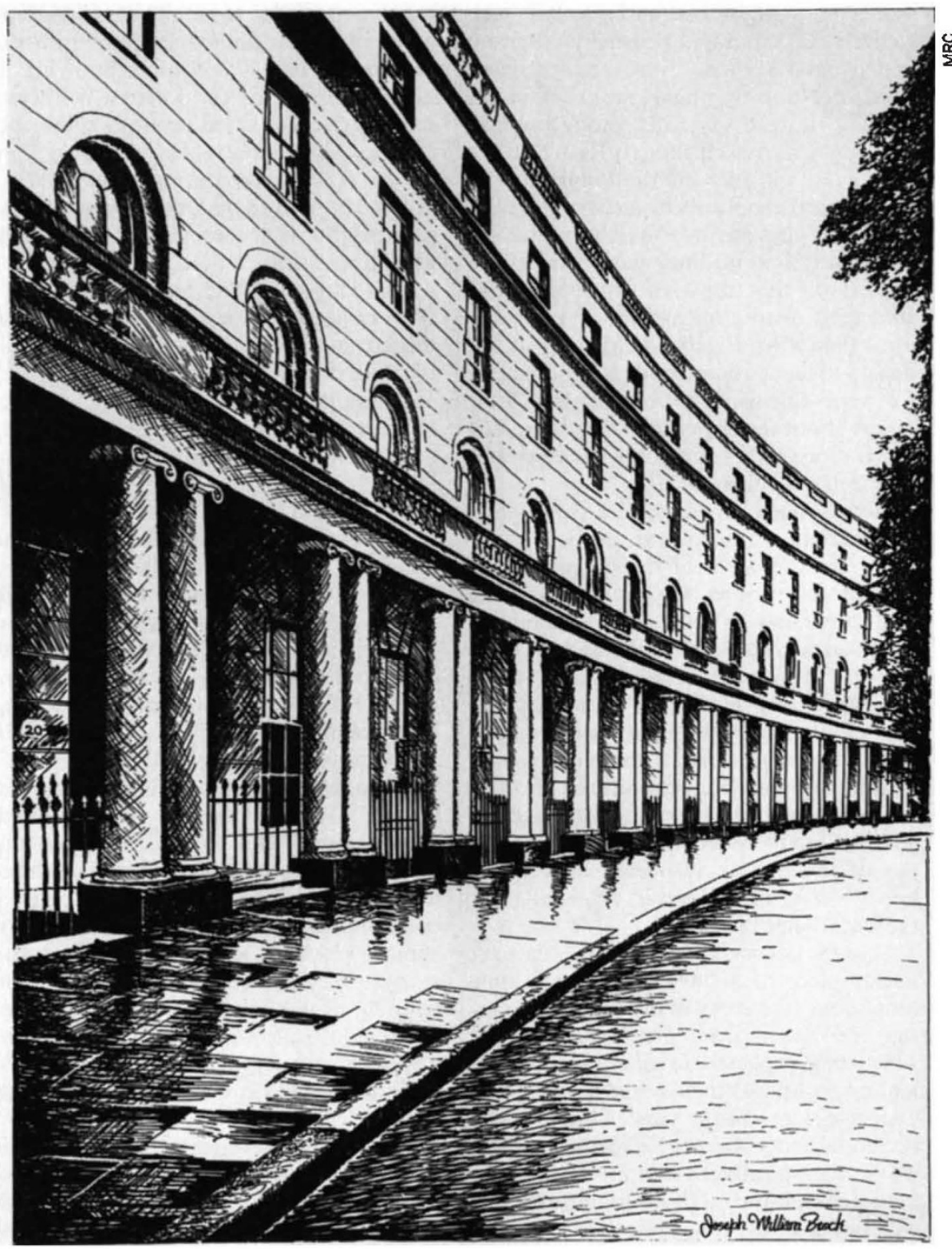

Park Crescent - home of Britain's Medical Research Council since 1961, built to conform with the Georgian façade of the other buildings surrounding it.

insulin used as a model for relations between the MRC and the pharmaceutical industry, experimental radiobiology and clinical research. There is also an essay about the National Institute for Medical Research and a biographical essay on Sir Walter Fletcher, the council's first secretary.

What is striking is the extent to which the council created knowledge and being the only one for which free institutional treatment was provided under the terms of the 1911 National Insurance Act. An apparently late appreciation that science might permit the state-provided funds to be spent to the best advantage led to the inclusion of a clause in the act setting aside one penny per person insured (amounting to $£ 56,000$ a year) for research. It seems clear that this research 
element was regarded as a minor point of drafting, although it turned out to be a prescient one. Whether it was intended that research be limited to tuberculosis is not now clear, although Bryder thinks it was. Whether it was or not, pressure was immediately applied to enlarge its scope.

Today, the notion of objectively assessing new forms of treatment to see whether they achieve anything or nothing through controlled clinical trials is commonplace, if not always uncontroversial. In Britain this can be traced back to the MRC's therapeutic trials committee which, among other things, tested calciferol, testosterone and the suplhanilamides. Interestingly, the committee had no statistician: even though R. A. Fisher pioneered the idea of randomization in agricultural experiments and worked with the MRC in several research arenas, he apparently had no links with it. Possibly because of this, the idea of the randomized controlled clinical trial had to wait until 1946 when Bradford Hill used such a design to test streptomycin as a treatment for tuberculosis. The results left little doubt about the benefits of the drug. But much more important, they ushered in a new era of medicine.

Just as innovative but, with the benefit of hindsight, rather more suspect results had been the work of the committee of quantitative problems in human nutrition, first convened in 1922 . The committee analysed working-class spending on food and found that the working classes were "ignorant and inefficient". In fact, as Celia Petty points out in her essay on the relationships between research and public health, the data the committee collected "actually demonstrates that working class wives already made extremely efficient use of inadequate resources and had a better grasp of economic realities than their academic critics".

Lessons can be learned from this particular piece of history. The first is that those doing the study in the years between the two world wars presumably found what they expected to find (as Thomas Kuhn had told us they would). What was expected here was the view of one class of society about another. Nevertheless, the work was a novel attempt to "apply modern scientific methods to improve the well-being of an economically disadvantaged group". However, the fact that the wrong conclusion was drawn probably had far-reaching consequences as it supported the idea that the lower paid did not need more money, but more 'education' (this view seems to have resurfaced recently). In fact, they were simply underfed.

How difficult it is to apply science successfully to social problems. The irony revealed by Petty's essay is that the nutritional research did not directly alleviate the social problems which were its motivation, but rather led to better understand- ing of physiology and biochemistry. In the short term, it was science not society that benefited. The late Derek de Solla Price made much the same general point about science and technology. I think that if there is one thing that the research community should heed in this day and age, it is that particular lesson.

Our research institutions play large, though for most of us largely unknown, parts in our lives. We owe it to ourselves, as well as the institutions themselves, to try to understand them. There is a school of thought that understanding an institution or an activity requires knowing its history. This is not a notion to which scientists themselves often seem to subscribe, perhaps with good reason as I suggested above. It seems to me, however, that we fail at our peril to understand science and particularly how research can be harnessed to social change through political will and legislation or 'market forces'. We are not short of accounts of science as threads in the history of ideas. But this is the age of science by government, and anything that provides even a glimpse of how science drives social engineering through the interlocking committees that are the cogs of government machinery is profoundly to be welcomed.

These are essays academic in tone, and this is their strength and their weakness. They are well-documented and wellargued, but they are also rather circumscribed and tend to leave the reader slightly dissatisfied. Bryder's judgement on the MRC's contribution to the decline of tuberculosis is hardly rhadamanthine in its severity. Nevertheless, she does say that the reduction of the disease occurred largely independently of "medical intervention". But to find out what did cause its reduction, she refers the reader to two other books (neither of which I could find in a library). Booth's history of clinical research stops at the point the story starts to get interesting - the opening of the Clinical Research Centre. It is that institute's closure 20 years on that has been arousing passions recently. We really do need to know why this enterprise failed.

A final word of warning. This is administrative history - it depends for its raw material on official documentation. One does not have to sit through many committees, research or otherwise, to appreciate that what is written in the minutes bears only a limited resemblance to what has been said. I sometimes think historians should be more like the psychiatrists who believe nothing their patients tell them rather than like those who believe everything.

John Galloway is at the Cancer Research Campaign, 2 Carlton House Terrace, London SW1Y 5AR, UK. The views expressed here are his own.

\section{Darwin's legacy}

\section{Philip Kitcher}

The Metaphysics of Evolution. By David L. Hull. State University of New York Press: 1989. Pp.331. Hbk \$73.50, pbk \$24.95.

MANY practicing scientists have a stereotype of the philosopher of science which can be condensed into three characteristics: ignorant, interfering and insular. That stereotype derives from the suspicion that the philosopher of science is primarily in the business of telling the practitioners what they ought to be doing, and that this unwanted advice is given

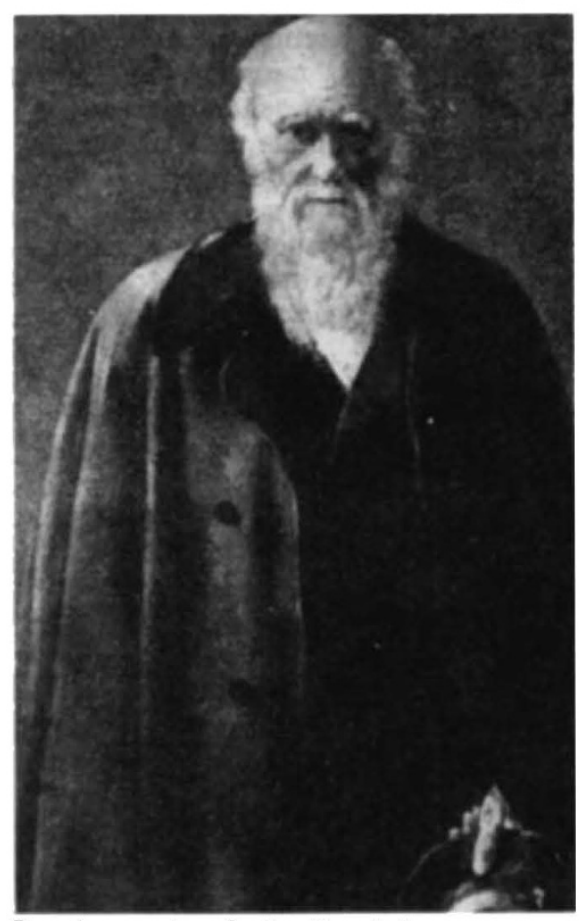

Darwin - not preferring the status quo.

from an olympian perspective.

Work in the philosophy of physics since the 1940s and in the philosophy of psychology since the 1960 s has belied the stereotype, for philosophers in these subdisciplines have demonstrated their ability to draw on the substance of the sciences and to contribute to the clarification of theoretical disputes. During the past two decades, however, biology - particularly evolutionary biology - has been the most exciting area for exchange of ideas between philosophers and scientists. David Hull is one of those most responsible for this dialogue, and many of his contributions to it are brought together in this volume.

Hull is a vigorous campaigner against what he calls "intellectual territoriality", and his essays range over issues in metaphysics, history of science, general history, systematics, evolutionary theory and sociology. He offers insights into the reception of darwinism, and uses a study 